\title{
IMPACT OF CYCLING ON MENTAL HEALTH AND SELF-ESTEEM IN THE ELDERLY
}

\author{
Heru Herdiana Nugraha ${ }^{1}$, Nurlan Kusmaedi², Yusup Hidayat ${ }^{3}$, \\ Hasanul Fitrah Alba ${ }^{4}$ \\ Universitas Pendidikan Indonesia ${ }^{1,2,3}$, Universitas Mitra Karya ${ }^{4}$ \\ heruherdiana16@gmail.com ${ }^{1}$,nurlankusmaedi@gmail.com² ${ }^{2}$, \\ yusuf_h@upi.edu ${ }^{3}$, hasanulfitrahalba@gmail.com ${ }^{4}$
}

\begin{abstract}
The elderly are an age group that is vulnerable to changes due to the aging process and these changes cause problems that can affect the quality of life of the elderly. This study aims to find out the impact of cycling activities on mental health and self-esteem in the elderly. Metode research used in this study method Causal-comparative research (ExpostFacto). The design used in this study is criterion-groupdesign. This research uses sampling techniques using non probability sampling,i.e. by purposive sampling. The sample in this study amounted to 40 people divided into 2 groups between the elderly who were active cycling and the elderly who were not active in sports. This study used two measuring instruments in the form of questionnaires, namely Depression Anxiety Stress Scale 42 (WATERSHED 42) and Self-Esteem Rating Scale (SERS). Data analysis is processed using SPSS software version 25. The results showed that there were differences in mental health and self-esteem between elderly people who were actively cycling and the elderly who were not active in sports judging from the t-test with Sig. (2 Tailed $<0.05$ by drawing Sig conclusions. (2-tailed) mental health by $0,000<0.05$ and self-esteem by $0.000<0.05$. That is, cycling activities have an impact on the mental health and self-esteem of the elderly.
\end{abstract}

Keywords: Bicycles, Mental Health, Self-Esteem, Elderly

Accepted: $19^{\text {th }}$ of January 2022

Correspondence author: Heru Herdiana Nugraha, Universitas Pendidikan Indonesia. E-Mail: heruherdiana16@gmail.com

DOI http://dx.doi.org/10.31851/hon.v5i1.7056

\section{(c) (i) (2)}

Jurnal Halaman Olahraga Nusantara licensed under a Creative Commons Attribution-ShareAlike 4.0 International License

\section{INTRODUCTION}

Exercise is no longer a means of meeting the needs for the body to be healthy, more than that exercise can now be a healthy life style. Sports activities are certainly various types, such as running, swimming, cycling and many others. Cycling can help to improve fitness and cycling is also one form of aerobic exercise. Bicycle riding has been researched in various ways as a health-enhancing recreational activity (Kaczynski \& Henderson, 2007; Dunlap et al., 2020). Cycling 
activities also not only have a positive impact on health, but provide benefits to a person's mental health. In addition, recreational cycling provides physiological and social benefits as well as contributes significantly to the rider's sense of happiness (Yu and Tian, 2013; Chen \& Chancellor, 2019).

One indicator of the level of public health is the increasing life expectancy. With the increasing life expectancy, it means more and more elderly residents (elderly). The elderly are an age group that is prone to changes due to the aging process. These changes cause problems that can affect the quality of life of the elderly. There are several categories of old age, WHO classifies old age consisting of middle age (middle age) age group 45-59 years, elderly age group 60-70 years, old age(old)age group between 75-90 years, very old age (very old) age group over 90 years. According to the Ministry of Social Affairs, the number of elderly in Indonesia is more than $10 \%$ of the population by 2020 . Currently the population in the country reaches 269.9 million people. The population over the age of 60 reached 28.7 million people. This means that more than $10.6 \%$ of indonesia's population is elderly.

The fact that is happening today in all countries is the lack of active elderly in doing physical activity. With the growth of the elderly population, it is a challenge to promote active transportation among the elderly as a health promotion (Wanner et al., 2012; Zhang et al., 2016). According to some of the above studies, it can be concluded that the elderly are less active in doing physical activity. There are several factors that affect the elderly not active in exercising, such as examples of lack of support from family, lack of elderly receiving information about the importance of maintaining health. However, older adults also report many barriers to physical activity including fear of injury, health limitations and lack of motivation (Lees et al., 2005; Greenwood-Hickman et al ; Witcher et al., 2016).

Depression, which is associated with mental health, has something to do with elderly self-esteem. Where depression can affect the decline of elderly selfesteem. Depressed individuals often have poor self-concept and experience feelings of low self-esteem (Fox, 2000; White et al., 2009). Although individuals may 
differ, new vertical evidence suggests that self-esteem tends to increase from adolescence to middle adulthood, peaking around age 50 to 60 , and then declining rapidly into old age (Orth and Robins 2014). Mental health and self-esteem are interconnected and affect each other.

The high low self-esteem of the elderly, can be influenced by physical activity factors, one of which is cycling activities. Approximately $60 \%$ of research reports show that physical activity is positively associated with people participating in physical activity and increasing self esteem levels (McAuley et al. 2000). It also seems obvious the relationship of physical activity to self-esteem and self-efficacy (McAuley \&rudolph, 1995; Batista et al., 2016) as well as for emotional well-being appear to be evidence of the positive effects of physical activity in reducing symptoms of depression and anxiety (Brown, Wang and Ward, 1995; Batista et al., 2016).

Regular physical activity may reduce the risk of chronic disease, falls, depression and dementia in older adults (Ahlskog et al., 2011; Brown et al., 2012 ; Samra et al., 2018). One form of physical activity is with cycling activities. Cycling is an activity involving physical and psychosocial (Leslie et al. 2004). This is because cycling is an activity that can be done outdoors, relax, feel the natural atmosphere and recreation. Cycling and walking are obviously popular activities, whether for sports, recreation, sports, or simply for relaxation and enjoyment of the outdoors (Turner, Shawn; Sandt, Laura; Toole, Jennifer; Benz, Robert; Patten 2006). When looking at psychological factors, older adults report that the benefits they get from physical activity are helpful in maintaining mobility and improving physical and mental health (Witcher et al., 2016; Samra et al., 2018). Mactivation affects a person's interests and willingness in carrying out an activity. Influence from inside and outside the individual, encouraging a person to do or carry out his or herdesires. Giving motivation to individuals gives a lot of energy. All of that can be felt when motivation has penetrated oneself (Alba et al., 2019).

There are several other references that physical activity can affect mental health such as statements from (Mummery, Caperchione, and Schofield 2003) 
suggesting that involvement in moderate activity on a regular basis or as part of leisure, exercise, work, and transportation can provide a number of psychological benefit factors. These include cognitive function, reduction of symptoms of depression and anxiety disorders, and improved self-control and self-ability. There are also other references that cycling activities are related to mental health. Statement from Synek (2019) "thereis ample evidence that cycling to work correlates positively with physical activity and hence physical health particularly in regard to the human cardiovascular system and mental health" or it can be interpreted that there is ample evidence that cycling to the workplace is positively correlated with physical activity and therefore physical health, especially with regard to the human cardiovascular system and mental health.

Then based on the results of research from Crane (2014) stated the results of his research, namely "The findings reveal that formen surveyed for this study, frequent (weekly) cycling is specifically associated with physical health facets of QoL and that any frequency of cycling is positively associated with psychological wellbeing" revealed that the results From this research survey, cycling is often (weekly) specifically associated with the physical health aspects of quality of life and that each frequency of cycling is positively associated with psychological wellbeing. And based on the results of research from Raglin (in Callaghan, 2004) states that "General findings show that exercise improves mood state and self-esteem, and lowers stress dispositions, a factor known for aggravating mental and physical disorders alike" or exercise improves mood and self-esteem, and decreases the disposition of stress, a factor known to worsen mental and physical disorders. In addition, based on Bhamani's research (2015) entitled "Depression and its Association with functional status physical activity in the elderly in Karachi, Pakistan" states that improving functional status and physical level is a method of cost-effective, both as a preventive health promotion and self-management strategies to address the mental health of the elderly,especially in low and middleincome countries such as Pakistan and need more research in this field. 
Accredited

SINTA 3

On that basis,researchers assume that physical activity through cycling activities can maintain the mental health of the elderly and also increase elderly self-esteem. Therefore, the purpose of this study is to find out the impact of cycling activities on mental health and self-esteem in the elderly.

\section{METHOD}

The of research used in this study is a quantitative approach to the Causalcomparative research (Expost-Facto) method. The purpose of causal comparative is the researcher's effort to determine the cause or consequences of differences that already exist between or between groups of individuals. Expost-facto research is a study in which free variables have occurred when researchers begin with the observation of bound variables in a study (Fraenkel, 2012). The design used in this study was criterion-group design, selecting two or more different groups based on specific variables of concern and comparing them based on variables or some other variable (Suherman \&Rahayu, 2015).

The sample in this study is lansia located in Pangandaran Subdistrict, using sampling techniques using non probability sampling,namely by purposive sampling. The samples were aged 45-59 years(middle age)and ages 60-74 (elderly)years with a total sampleof 40 people, divided into 4 groups of samples, each group of 10 people.

The instrument used in this study is depression anxiety stress scale 42 (DASS 42)which consists of 42 statement items and Self-Esteem Rating Scale (SERS)which consists of 40 items of rating. The instruments used have been adopted and have been translated from English to Indonesian and from Indonesian to English and discussed with expert judments.

Dass 42 has a discriminant validity level and has a rehabilitation value of 0.91 which is based on Cronbach's Alphaassessment. The reliability of the DASS was excellent, and the measure possessed adequate convergent and discriminant validity (Crawford and Henry 2003). This instrument has a validity rate of 0.341 0.969 and reliability of 0.978 
In the Self Estem Rating Scale (SERS) there are 40 statement items, this intrusion validity test has been studied by Nugent in a study entitled "AValidity Study of Two Forms of the Self-Esteem Rating Scale". SERS' rating scale is used in clinical assessments on self esteem Nugent \& Thomas (Fischer and Corcoran, 2000) describes the reliability of SERS, namely: "The SERS has excellent internal consistency, with an alpha of 0.97. The standard error of measurement was 5.67. Data on stability were not reported'.

\section{RESULTS AND DISCUSSIONS}

Data collected through the instrument angket,then processed and analized using a ststistic approach. The data analyzed in this study is data from the results of Mental Health questionnaires using Depression Anxiety Stress Scale 42 (WATERSHED 42), Self-Esteem questionnaire using Self-Esteem Rating Scale (SERS) in the bicycle community located in Pangandaran District.Hypothesis testing is done using independent analysis of t-test samples. Confidence interval value of $95 \%$ and significant value of $<0.05$ by making a conclusion decision when Sig. $(2$-tailed $)<0.05$ means $\mathrm{H}_{0}$ is rejected and $\mathrm{H} 1$ is accepted. Here are the results of the research data test:

Table 1. Mental Health Hypothesis Test of elderly people aged 45-59 years Independent Samples Test Levene's Test for Equality of t-test for Equality of Variances Means

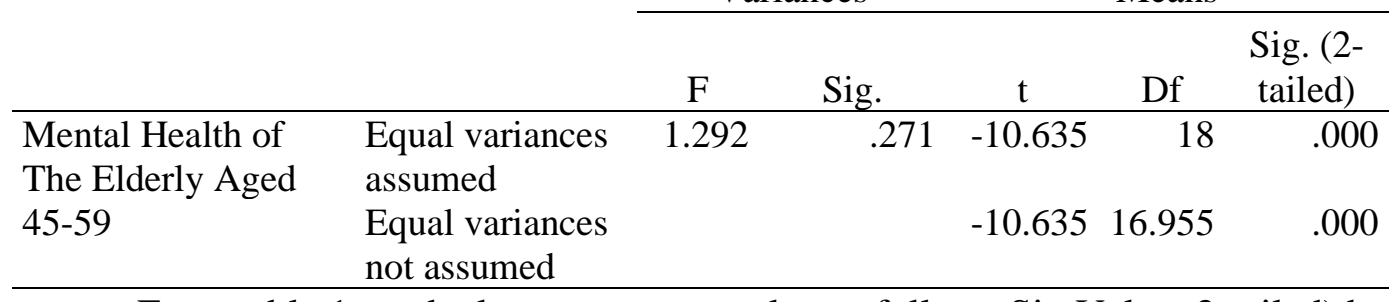

From table 1 can be known some results, as follows Sig Value. 2-tailed) by $0,000<0.05$. That is, there is a difference in mental health in the elderly aged 4559 years between those who are active cycling and those who are not active insports. Physical activity, defined as either homework, exercise, leisure activities, work activities, or general physical activity has been found to improve quality of life in the elderly (Poon and Fung 2008; Rejeski \& Mihalko, 2001). Physical 
activity through cycling activities that are carried out not only has a positive influence on the improvement of physical fitness, but can improve the working function of the human brain, especially in cognitive work and mental health. In addition there are also those who get "The benefits ofphysical activity, on both physical as well as mental health of the elderly have been shown by a number of studies" (Bhamani et al. 2015 ; Gauvin, 2003). Which means that the benefits of physical activity, both for the physical and mental health of the elderly have been shown by a number of studies.

Some studies have found that physical activity may moderate the relationship between mental health or physical health status and bodily function (Yuan et al. 2020; Hu and Yang, 2018; Palmer et al., 2012). Physical activity that is recommended to maintain mental health is an activity that is aerobic and recreational sports such as walking, running, playing or cycling, because of the activity.These physical benefits bring social and mood benefits. In its performance it must consider the frequency and duration of physical activity. This is as revealed by (Haralambous et al, 2003) in elena research (2011) recommends 30 minutes of walking at a moderate pace on most days of the week, or 150 minutes of moderate activity per week which is enough to maintain health. To maintain the health of the elderly physically or psychologically,it is necessary to have moderate-intensity aerobic physical activity and not competition. Elderly people who often do regular cycling activities at least 2 times a week can show better mental health compared to the elderly who are not active cycling.

Table 2. Self-Esteem Hypothesis Test of elderly aged 45-59 years

\begin{tabular}{llcccccc}
\hline \multicolumn{3}{c}{ Independent Samples Test } \\
\hline & \multicolumn{4}{c}{$\begin{array}{c}\text { Levene's Test for } \\
\text { Equality of } \\
\text { Variances }\end{array}$} & \multicolumn{3}{c}{$\begin{array}{c}\text { t-test for Equality of } \\
\text { Means }\end{array}$} \\
\cline { 2 - 7 } & & F & Sig. & t & Df & $\begin{array}{c}\text { Sig. (2- } \\
\text { tailed) }\end{array}$ \\
\hline $\begin{array}{l}\text { Self-esteem of } \\
\text { elderly aged 45-59 }\end{array}$ & $\begin{array}{l}\text { Equal variances } \\
\text { assumed }\end{array}$ & .709 & .411 & 12.039 & 18 & .000 \\
& $\begin{array}{l}\text { Equal variances } \\
\text { not assumed }\end{array}$ & & & 12.039 & 16.936 & .000 \\
\hline
\end{tabular}


Furthermore, based on table 2 on the calculation of self-esteem of elderly aged 45-59 with Sig value. (2-tailed) showed results of $0,000<0.05$ which means there is a difference in self-esteem in the elderly aged 45-59 years between those who are actively cycling and those who are not actively exercising. An individual's level of self-esteem affects health behaviors, motivations and lifestyle choices. Collingwood (2000) stated that physical exercise can improve self-esteem. That way this cycling activity can have a positive impact on elderly self-esteem. Participation in sports and physical activity can affect mental well-being, boosting self-esteem (Howells and Bowen 2016; The Mental Health Foundation, 2013). According to Tremblay (2000) found that the association between physical activity and academic achievement was weak but participation in physical activity was positively associated with higher levels of self-esteem. Then Barton (2012) found a significant positive change in self-esteem after doing exercise. Active physical activity, of course, has a positive effect on all ages including the elderly. These positive changes include psychological well-being including mental health and self-esteem in it.

Table 3. Mental Health Hypothesis Test of elderly people aged 60-74 years Independent Samples Test

\begin{tabular}{|c|c|c|c|c|c|c|}
\hline & \multicolumn{2}{|c|}{$\begin{array}{c}\text { Levene's Test for } \\
\text { Equality of Variances }\end{array}$} & \multicolumn{3}{|c|}{$\begin{array}{c}\text { t-test for Equality of } \\
\text { Means }\end{array}$} \\
\hline & & $\mathrm{F}$ & Sig. & $\mathrm{t}$ & Df & $\begin{array}{l}\text { Sig. }(2- \\
\text { tailed })\end{array}$ \\
\hline \multirow[t]{2}{*}{$\begin{array}{l}\text { Mental health of the } \\
\text { elderly aged } 60-74\end{array}$} & $\begin{array}{l}\text { Equal } \\
\text { variances } \\
\text { assumed }\end{array}$ & 1.038 & .322 & -9.907 & 18 & .000 \\
\hline & $\begin{array}{l}\text { Equal } \\
\text { variances not } \\
\text { assumed }\end{array}$ & & & -9.907 & 17.290 & .000 \\
\hline
\end{tabular}

From table 3 can be known some results, as follows Sig Value. 2-tailed) by $0,000<0.05$. That is, there is a difference in mental health in the elderly aged $60-$ 74 years between those who are active cycling and those who are not active insports. Individuals with high levels of physical activity had higher quality of life scores compared to low levels of physical activity, both in those with high and low mental health scores (Yuan et al. 2020). Cycling activities can be one of the 
Accredited

SINTA 3

solutions to the problems experienced by the elderly, especially the elderly who are prone to stress. According to Petroski (2008) in his research proves the importance of an active lifestyle in preventing mental health problems in the elderly. Neeser (2005) revealed that physical activity that can have a direct influence on mental health is aerobic exercise and endurance that ranges from 30-40 minutes. Physical activity activities that can be done as a good starting point such as hiking and cycling. From cycling activities other benefits for the elderly are getting support from community colleagues, sharing stories so as to increase the confidence of the elderly.

Table 4. Self-Esteem Hypothesis Test of elderly aged 60-74 years Independent Samples Test

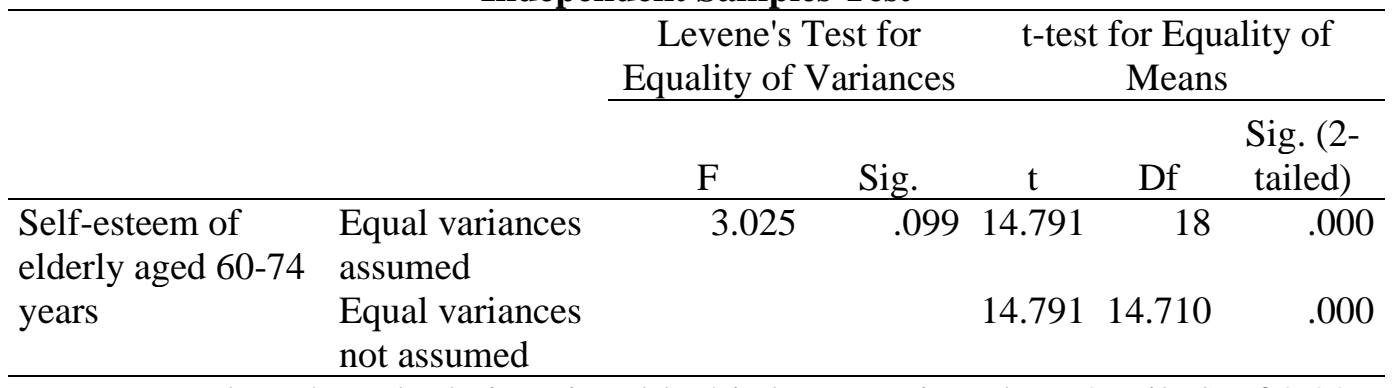

Based on the calculations in table 4 is known, sig value. 2-tailed) of $0,00<$ 0.05 which means there is a difference in self-esteem in the elderly aged 60-74 years between those who actively cycle and those who are not actively exercising. Involvement in regular exercise and physical activity programs that improve skills, knowledge, fitness, and health are associated with improved self-perception (Fox, 1997; Spence, McGannon, and Poon 2005). According to Ferdowsi (2010) reported that significant differences in self-esteem and mental health between the experimental group and the control group after 12 weeks of aerobic exercise. Moral-García (2018) said in his research, elderly people who do physical activity exercises regularly show higher positive self-esteem. That way the elderly who are active cycling will show a higher level of self-esteem and vice versa, who are not active cycling shows a higher level of self-esteem low. 


\section{CONCLUSION}

Based on the results of research and discussion, it can be concluded that cycling activities can have a positive impact on mental health and self-esteem of elderly aged 45-55 years (middle age) and elderly aged 60-74 years (elderly), and through cycling activities there are differences in mentalhealth and self-esteem. among the elderly who are actively cycling and not actively exercising. The recommendations for the next study expanded the variables and focused on factors based on gender, educational background, economic class.

\section{REFERENCES}

Alba, H. F., Mulyana, \& Subarjah, H. (2019). The effect of weight training models and motivational exercises on body fat and body mass index (BMI). Journal of Sports Science, 18(2), 112-119.

Barton, Jo, Murray Griffin, and Jules Pretty. 2012. "Exercise-, Nature- and Socially Interactive-Based Initiatives Improve Mood and Self-Esteem in the Clinical Population." Perspectives in Public Health 132(2):89-96. doi: $10.1177 / 1757913910393862$.

Batista, Marco, Delgado Sixto Cubo, Samuel Honório, and Júlio Martins. 2016. "The Practice of Physical Activity Related to Self-Esteem and Academical Performance in Students of Basic Education." Journal of Human Sport and Exercise 11(2):297-310. doi: 10.14198/jhse.2016.112.03.

Bhamani, Mehreen Anwar, Murad Moosa Khan, Mehtab S. Karim, and Mohammed Umer Mir. 2015. "Depression and Its Association with Functional Status and Physical Activity in the Elderly in Karachi, Pakistan." Asian Journal of Psychiatry 14(2014):46-51. doi: 10.1016/j.ajp.2014.12.004.

Callaghan, P. 2004. "Exercise: A Neglected Intervention in Mental Health Care?" Journal of Psychiatric and Mental Health Nursing 11(4):476-83. doi: 10.1111/j.1365-2850.2004.00751.x.

Chen, Li Hsin, and H. Charles Chancellor. 2019. "A Conceptual Framework for Integrating Bicycle Friendliness into Community Development." Community Development 50(5):589-606. doi: 10.1080/15575330.2019.1663226.

Collingwood, T. R., J. Sunderlin, R. Reynolds, and H. W. Kohl. 2000. "Physical Training as a Substance Abuse Prevention Intervention for Youth." Journal of Drug Education 30(4):435-51. doi: 10.2190/RVUE-9XW7-TYRQ-EJR8.

Crane, Melanie, Chris Rissel, Christopher Standen, and Stephen Greaves. 2014. "Associations between the Frequency of Cycling and Domains of Quality of Life." Health Promotion Journal of Australia 25(3):182-85. doi: 
10.1071/HE14053.

Crawford, John R., and Julie D. Henry. 2003. "The Depression Anxiety Stress

Scales (DASS): Normative Data and Latent Structure in a Large Non-Clinical

Sample." British Journal of Clinical Psychology 42(2):111-31. doi: 10.1348/014466503321903544.

Dunlap, Rudy, Jeff Rose, Sarah H. Standridge, and Courtney L. Pruitt. 2020.

"Experiences of Urban Cycling: Emotional Geographies of People and Place."

Leisure Studies 00(00):1-14. doi: 10.1080/02614367.2020.1720787.

Elena, Sabau, Niculescu Georgeta, Gevat Cecilia, and Lupu Elena. 2011. "The Attitude of the Elderly Persons towards Health Related Physical Activities." Procedia - Social and Behavioral Sciences 30:1913-19. doi: 10.1016/j.sbspro.2011.10.372.

Ferdowsi, Mohammad Hassan, Fateme Marashian, and Seyed Hussein Marashian. 2010. "The Effects of 12-Week Aerobic Exercises on Rate of Mental Health in Male Students of Ahvaz Payam Noor University." Human Movement 11(2):167-71. doi: 10.2478/v10038-010-0021-3.

Fraenkel, J. R., Wallen, N. E., \& Hyun, H. H.(2012). How to Design and Evaluate Research in Education. In McGraw-Hil (Vol. 53).

Howells, Kristy, and Jo Bowen. 2016. "Physical Activity and Self-Esteem: 'Jonny's Story'." $\quad$ Education 3-13 44(5):577-90. doi: 10.1080/03004279.2016.1171572.

Leslie, Eva, Ester Cerin, Christopher J. Gore, Alexis St George, Adrian Bauman, and Neville Owen. 2004. "Gender, Age, and Educational-Attainment Differences in Australian Adults' Participation in Vigorous Sporting and Fitness Activities." Journal of Physical Activity and Health 1(4):377-88. doi: 10.1123/jpah.1.4.377.

McAuley, Edward, Bryan Blissmer, Jeffrey Katula, Terry E. Duncan, and Shannon L. Mihalko. 2000. "Physical Activity, Self-Esteem, and Self-Efficacy Relationships in Older Adults: A Randomized Controlled Trial." Annals of Behavioral Medicine 22(2):131-39. doi: 10.1007/BF02895777.

Moral-García, José Enrique, Daniel Orgaz García, Sergio López García, Mario Amatria Jiménez, and Rubén Maneiro Dios. 2018. "Influence of Physical Activity on Self-Esteem and Risk of Dependence in Active and Sedentary Elderly People." Anales de Psicología 34(1):162-66. doi: 10.6018/analesps.34.1.294541.

Mummery, W. K., C.M. Caperchione, and G.M. Schofield. 2003. "Dose-Response Effects of Physical Activity on Mental Health Status in Older Adults." Medicine \& Science in Sports \& Exercise 35(Supplement 1):S215. doi: 10.1097/00005768-200305001-01191. 
Orth, Ulrich, and Richard W. Robins. 2014. "The Development of Self-Esteem."

Current Directions in Psychological Science 23(5):381-87. doi: 10.1177/0963721414547414.

Petroski, Edio Luiz. 2008. "Atividade Física e Estado de Saúde Mental de Idosos Physical Activity and Mental Health." 42(2):302-7.

Poon, Cecilia Y.M., and Helene H. Fung. 2008. "Physical Activity and Psychological Well-Being among Hong Kong Chinese Older Adults: Exploring the Moderating Role of Self-Construal." International Journal of Aging and Human Development 66(1):1-19. doi: 10.2190/AG.66.1.a.

Samra, Pamela K., Lynne Parkinson, Deborah Power, Anthony Schneiders, Corneel Vandelanotte, J. Stephanie, and Central Queensland. 2018. "Physical Activity Attitudes, Preferences, and Experiences of Regionally-Based Australia Adults 65+ Years." Journal of Aging and Physical Activity.

Spence, John C., Kerry R. McGannon, and Pauline Poon. 2005. "The Effect of Exercise on Global Self-Esteem: A Quantitative Review." Journal of Sport and Exercise Psychology 27(3):311-34. doi: 10.1123/jsep.27.3.311.

Suherman, Adang \& Rahayu, Indri. (2015). Research Methods, UPI: Imu Sports Synek, Stefan, and Joerg Koenigstorfer. 2019. "Health Effects from Bicycle Commuting to Work: Insights from Participants of the German CompanyBicycle Leasing Program." Journal of Transport and Health 15(August):100619. doi: 10.1016/j.jth.2019.100619.

Tremblay, M. S., J. W. Inman, and J. D. Willms. 2000. "The Relationship between Physical Activity, Self-Esteem, and Academic Achievement in 12-Year-Old Children." Pediatric Exercise Science 12(3):312-23. doi: 10.1123/pes.12.3.312.

Turner, Shawn; Sandt, Laura; Toole, Jennifer; Benz, Robert; Patten, Robert. 2006.

"Federal Highway Administration University Course on Bicycle and Pedestrian Transportation." (July): 452.

White, Karen, Tony Kendrick, and Lucy Yardley. 2009. "Change in Self-Esteem, Self-Efficacy and the Mood Dimensions of Depression as Potential Mediators of the Physical Activity and Depression Relationship: Exploring the Temporal Relation of Change." Mental Health and Physical Activity 2(1):44-52. doi: 10.1016/j.mhpa.2009.03.001.

Witcher, Chad S. G., Nicholas L. Holt, Wendy Young, Chris Blanchard, Donna Murnaghan, and John C. Spence. 2016. "Physical Activity Perceptions and Influences among Older Adults in Rural Nova Scotia." Canadian Journal on Aging 35(1):115-29. doi: 10.1017/S0714980815000598.

Yuan, Yemin, Jie Li, Zhengyue Jing, Caiting Yu, Dan Zhao, Wenting Hao, and Chengchao Zhou. 2020. "The Role of Mental Health and Physical Activity in 


\section{OLAHRAGA}

MUREAL JLIII KEOLDIRIGLAI
Jendral A. Yani Street Lorong Gotong Royong 9/10 Ulu Palembang South Sumatera

email jurnal: jurnalhon@univpgri-palembang.ac.id situs web: http://www.univpgri-palembang.ac.id
Accredited

SINTA 3

the Association between Sleep Quality and Quality of Life among Rural Elderly in China: A Moderated Mediation Model." Journal of Affective Disorders 273:462-67. doi: 10.1016/j.jad.2020.05.093.

Zhang, Yi, Chaoyang Li, Chuan Ding, Chunli Zhao, and Jianzhong Huang. 2016. "The Built Environment and the Frequency of Cycling Trips by Urban Elderly: Insights from Zhongshan, China." Journal of Asian Architecture and Building Engineering 15(3):511-18. doi: 10.3130/jaabe.15.511. 